\title{
ACCELERATING RATE CALORIMETRY TESTS OF LITHIUM-ION CELLS BEFORE AND AFTER STORAGE DEGRADATION AT HIGH TEMPERATURE
}

\author{
Omar Samuel Mendoza-Hernandez ${ }^{(1,2)}$, Shuichi Taniguchi ${ }^{(2)}$, Hiroaki Ishikawa ${ }^{(3)}$, Kohei Tanaka ${ }^{(4)}$, \\ Seisuke Fukuda ${ }^{(1,4)}$, Yoshitsugu Sone ${ }^{(1,4)}$, Minoru Umeda ${ }^{(1,2)}$ \\ (1) Japan Aerospace Exploration Agency, 3-1-1 Yoshinodai, Chuo-ku, Sagamihara, Kanagawa, 252-5210(Japan), \\ Email: sone.yoshitsugu@jaxa.jp \\ (2) Nagaoka University of Technology, 1603-1 Kamitomioka, Nagaoka, Niigata, 940-2188 (Japan), \\ Email: mumeda@vos.nagaokaut.ac.jp \\ (3) Industrial Technology Institute of Ibaraki Prefecture, Ibaraki, Japan \\ (4) The Graduate University of Advanced Studies, SOKENDAI, 3-1-1 Yoshinodai, Chuo-ku, Sagamihara, Kanagawa, \\ 252-5210(Japan)Email: sone.yoshitsugu@jaxa.jp
}

\begin{abstract}
Understanding the behavior of Li-ion cells during thermal runaway is critical to evaluate the safety of these energy storage devices under outstanding conditions. Li-ion cells possess a high energy density and are used to store and supply energy to many aerospace applications. Incidents related to the overheating or thermal runaway of these cells can cause catastrophic damages that could end up costly space missions; therefore, thermal studies of Li-ion cells are very important for ensuring safety and reliability of space missions. This work evaluates the thermal behavior of Li-ion cells before and after storage degradation at high temperature using accelerating rate calorimeter (ARC) equipment to analyze the thermal behavior of Li-ion cells under adiabatic conditions. Onset temperature points of self-heating and thermal runaway reactions are obtained. The onset points are used to identify non-self-heating, self-heating and thermal runaway regions as a function of state of charge. The results obtained can be useful to develop accurate thermo-electrochemical models of Li-ion cells.
\end{abstract}

\section{INTRODUCTION}

Li-ion cells are an essential part of the power systems for satellites, rockets and spacecraft, they serve as energy storage devices and provide power during eclipse time. Aerospace applications demand compact and lightweight battery systems, this implies the use of devices with a high energy density which due to their high energetic components are not inherently safe. Liion cells possess a high energy density but can cause catastrophic incidents that could end up costly space missions, those incidents are mainly related to the overheating or thermal runaway of Li-ion cells which can lead to fire and explosion.

The thermal runaway behavior of a Li-ion cell is dominated by the exothermic reactions between its electrolyte and electrode materials [1-3]. Thermal runaway occurs when the exothermic reactions go out of control, thus the self-heating rate of the cell increases to the point that it begins to generate more heat than what can be dissipated [4,5]. Understanding the behavior of Li-ion cells during thermal runaway is very important for ensuring their safety and reliability.

The use of accelerating rate calorimeter (ARC) equipment allows the thermal analysis of Li-ion cells under adiabatic conditions [2, 3, 5-7]. ARC measurements are useful to obtain onset temperature points of self-heating and thermal runaway reactions. Recently, safety concerns related to use of damaged or degraded Li-ion cells have increased, mainly focusing on the thermal behavior of degraded cells, however, there are a few investigations on this matter. In this work, the thermal behavior of non-degraded and degraded Li-ion cells is analyzed by carrying out ARC measurements. Degradation tests were conducted by storing fully charged Li-ion cells at $80{ }^{\circ} \mathrm{C}$. Thermal mapping plots of degraded and non-degraded cells are made, these plots are used to identify non-self-heating, self-heating and thermal runaway regions as a function of state of charge. The results obtained can be used to develop accurate thermo-electrochemical models of Liion cells.

\section{EXPERIMENTAL METHODOLOGY}

Commercial $18650 \mathrm{Li}$-ion cells with a nominal capacity of $2550 \mathrm{mAh}$ were used in this work. The cathode and anode electrode materials are $\mathrm{LiCoO}_{2}$ and graphite.

\subsection{Storage degradation}

Li-ion cells were fully charged $(4.2 \mathrm{~V})$ and stored in a thermostatic chamber at $80{ }^{\circ} \mathrm{C}$ for 168 hours.

\subsection{Accelerating rate calorimetry tests}

Calorimetry tests were carried out at different state of charges utilizing an accelerating rate calorimeter (ARC $2000^{\mathrm{TM}}$, Columbia Scientific Industries). Once the cells were set to the desired state of charge, they were place inside the ARC cavity. A thermocouple was placed on the surface of the cell to record its temperature. The ARC tests were conducted following a Heat-WaitSearch method. During the heating step, the temperature 
of ARC's cavity is increased in periods of $5{ }^{\circ} \mathrm{C}$ follow by a waiting step of $30 \mathrm{~min}$ and a searching step of 5 min. If during the searching period a heating rate larger than $0.05{ }^{\circ} \mathrm{C} \mathrm{min}-1$ is detected, it is considered that a self-heating (exothermic) reaction has started, and then the ARC shifts to adiabatic mode and tracks the cell's temperature until the end of the exothermic reaction. If no exothermic reaction is detected, the next heating step is initiated. The ARC tests were carried out at $0,25,50$, 75 and $100 \%$ SOC.

\section{RESULTS AND DISCUSSION}

Fig. 1 shows the ARC measurements of non-degraded Li-ion cells at $0,25,50,75$ and $100 \%$ SOC. A temperature drop is observed at some SOCs, this likely due to the volatilization of the electrolyte. From the ARC measurements, onset temperature points of selfheating and thermal runaway reactions are obtained by tracking the heating rate of the cells when an exothermic reaction has been detected. We consider that a self-heating reaction has started when the cell heating rate is larger than $0.05{ }^{\circ} \mathrm{C} \mathrm{min}^{-1}$, and thermal runaway reaction starts when the cell heating rate is larger than 1 ${ }^{\circ} \mathrm{C} \min ^{-1}$.

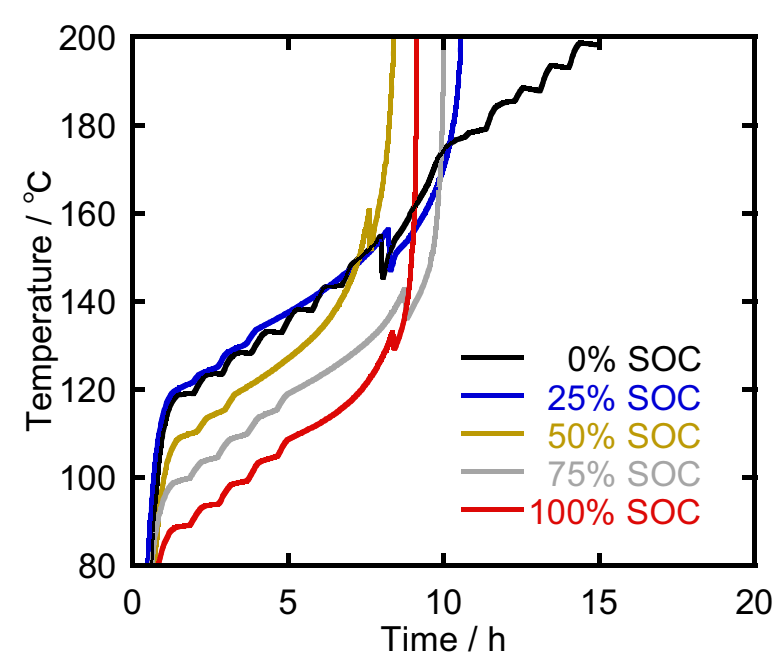

Figure 1. ARC measurements of non-degraded Li-ion cells at 0, 25, 50, 75 and 100\% SOC.

Tab. 1 shows the onset temperature points of selfheating and thermal runaway reactions for non-degraded Li-ion cells. It can be noticed that onset temperatures of the exothermic reactions tend to decrease by increasing the state of charge. This reflects the influence of the state of charge on the thermal stability of the electrode materials, where highly delithiated electrode materials become more reactive [8].
Table 1. Onset temperature point of self-heating and thermal runaway of non-degraded Li-ion cells.

\begin{tabular}{ccc}
\hline SOC (\%) & $\begin{array}{c}\text { Onset temperature of } \\
\text { self-heating }\left({ }^{\circ} \mathbf{C}\right)\end{array}$ & $\begin{array}{c}\text { Onset temperature } \\
\text { of Thermal } \\
\text { runaway }\left({ }^{\circ} \mathbf{C}\right)\end{array}$ \\
\hline 0 & 152.1 & - \\
25 & 130.2 & 173.4 \\
50 & 110.7 & 172.1 \\
75 & 121.2 & 165.3 \\
100 & 100.0 & 144.9 \\
\hline
\end{tabular}

Fig. 2 shows a thermal mapping plot of non-degraded cells, this plot summarizes the ARC results. Non-selfheating, self-heating and thermal runaway regions are identified as a function of SOC. In the non-self-heating (blue bars) region, no exothermic reactions take place. In the self-heating region (yellow bars) exothermic reactions with a heating rate larger than $0.05{ }^{\circ} \mathrm{C} \mathrm{min}-1$ occur. In the thermal runaway region (red bars) the heating rate of the exothermic reactions is larger than 1 ${ }^{\circ} \mathrm{C} \min ^{-1}$.

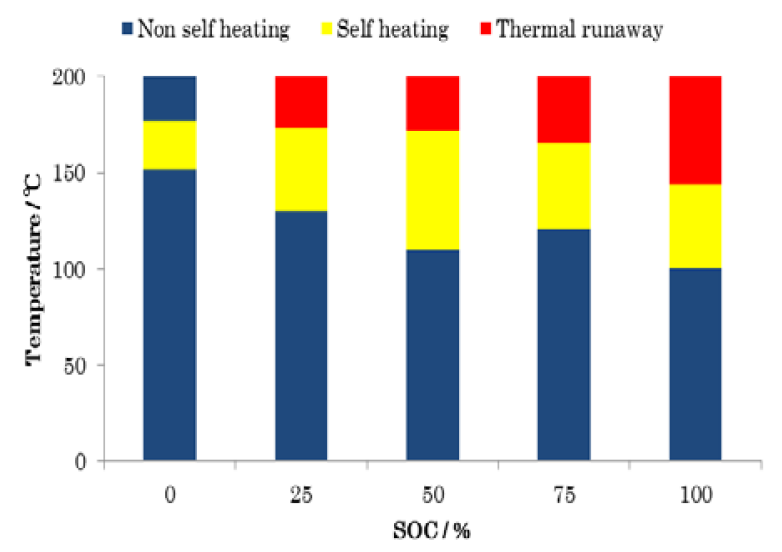

Figure 2. Thermal mapping of non-degraded cells as a function of SOC.

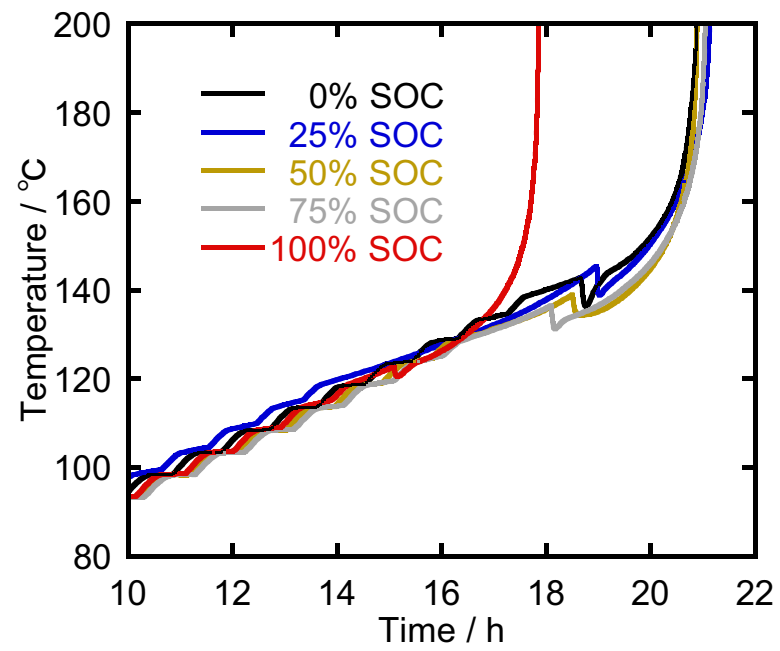

Figure 3. ARC measurements of degraded Li-ion cells at $0,25,50,75$ and $100 \%$ SOC. 
Fig. 3 shows the thermal behavior of degraded Li-ion cells during the ARC measurements at $0,25,50,75$ and $100 \%$ SOC. Tab. 2 summarises the onset temperature points of self-heating and thermal runaway reactions for the degraded cells. In the case of a degraded Li-ion cell, a thermal runaway reaction was observed at $0 \%$ SOC.

Table 2. Onset temperature point of self-heating and thermal runaway of degraded Li-ion cells.

\begin{tabular}{ccc}
\hline SOC (\%) & $\begin{array}{c}\text { Onset temperature of } \\
\text { self-heating }\left({ }^{\circ} \mathbf{C}\right)\end{array}$ & $\begin{array}{c}\text { Onset temperature } \\
\text { of Thermal } \\
\text { runaway }\left({ }^{\circ} \mathbf{C}\right)\end{array}$ \\
\hline 0 & 140.5 & 168.2 \\
25 & 120.3 & 173.9 \\
50 & 129.8 & 163.8 \\
75 & 125.3 & 167.6 \\
100 & 115.1 & 153.4 \\
\hline
\end{tabular}

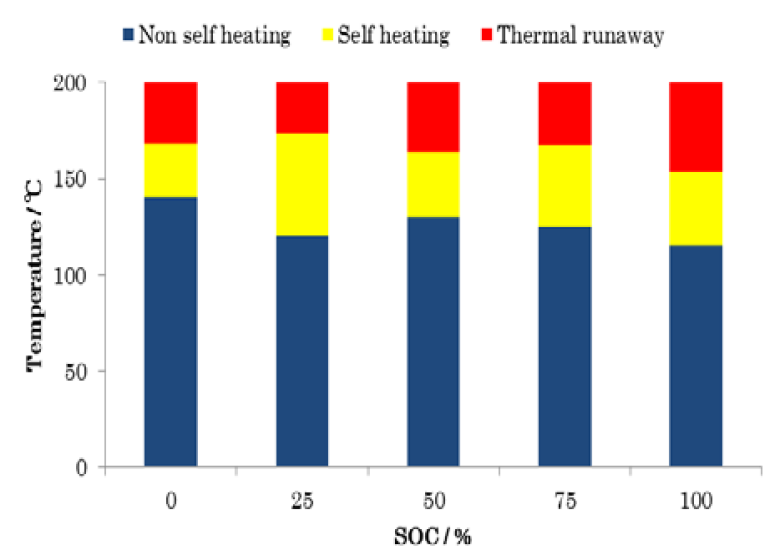

Figure 4. Thermal mapping of degraded Li-ion cells as a function of SOC.

Fig. 4 shows a thermal mapping plot of degraded Li-ion cells. At $0 \% \mathrm{SOC}$ a thermal runaway region is identified, while in the case of a non-degraded Li-ion cell any thermal runaway region is observed at $0 \%$ SOC. A thermal runaway reaction takes place when the exothermic reactions go out of control, the exothermic reactions usually start when the solid electrolyte interface (SEI), generated at the anode electrode material, reacts with the electrolyte and electrode materials [9]. Usually when a Li-ion cell is degraded, the SEI tends to grow, and this increment in the SEI might be accelerating the exothermic reactions until thermal runaway.

\section{CONCLUSIONS}

The thermal behavior of non-degraded and degraded Liion cells was analyzed by carrying out accelerating rate measurements. The ARC results were used to make thermal mapping plots, where non-self-heating, selfheating and thermal runaway regions are identified as a function of state of charge. The results suggest that degraded Li-ion cells tend to become thermally unstable at low state of charges. The results obtained can be used to develop a thermo-electrochemical model of Li-ion cells, which can be very useful to analyze the impact of the state of degradation of a Li-ion cell on its thermal stability.

\section{ACKNOWLEGMENT}

This research is partially supported by the 'International Joint Research Program for Innovative Energy Technology' of the Ministry of Economy, Trade and Industry (METI).

\section{REFERENCES}

1. T. D. Hatchard, D. D. MacNeil, A. Basu, J. R. Dahn. (2001). Thermal Model of Cylindrical and Prismatic Lithium-ion Cells. J. Electrochem. Soc. 148, A755-A761.

2. I. Uchida, H. Ishikawa, M. Mohamedi, M. Umeda. (2003). AC-Impedance Measurements during Thermal Runaway Process in Several Lithium/polymer Batteries. J. Power Sources 119121, 821-825.

3. J.S. Gnanaraj, E. Zinigrad, L. Asraf, H.E. Gottlieb, M. Sprecher, D. Aurbach, M. Schmidt. (2003). The Use of Accelerating Rate Calorimetry (ARC) for the Study of the Thermal Reactions of Li-ion Battery Electrolyte Solutions J. Power Sources 119-121, 794-798.

4. R.M. Spotnitz, J. Weaver, G. Yeduvaka, D.H. Doughty, E.P. Roth. (2007). Simulation of Abuse Tolerance of Lithium-ion Battery Packs. J. Power Sources 163, 1080-1086.

5. B.K. Mandal, A.K. Padhi, Z. Shi, S. Chakraborty, R. Filler. (2006). Thermal Runaway Inhibitors for Lithium Battery Electrolytes. J. Power Sources 161, 1341-1345.

6. H. Ishikawa, O. Mendoza, Y. Sone, M. Umeda. (2012). Study of Thermal Deterioration of Lithium-ion Secondary Cell Using an Accelerating Rate Calorimeter (ARC) and AC Impedance. J. Power Sources 198, 236-242.

7. O. S. Mendoza-Hernandez, H. Ishikawa, Y. Nishikawa, Y. Maruyama, M. Umeda. (2015). Cathode Material Comparison of Thermal Runaway Behavior of Li-ion Cells at Different State of Charges including Over Charge. J. Power Sources 280, 499-504.

8. Y. Furushima, C. Yanagisawa, T. Nakagawa, Y. Aoki, N. Muraki. (2011). Thermal Stability and Kinetics of Delithiated $\mathrm{LiCoO}_{2}$. J. Power Sources 196, 2260-2263.

9. P. Roder, B. Stiaszny, J. C. Ziegler, N. Baba, P. Lagaly, H. Wiemhofer. The Impact of Calendar Aging on the Thermal Stability of a $\mathrm{LiMn}_{2} \mathrm{O}_{4}$ $\mathrm{Li}\left(\mathrm{Ni}_{1 / 3} \mathrm{Mn}_{1 / 3} \mathrm{Co}_{1 / 3}\right) \mathrm{O}_{2} /$ graphite Lithium-ion Cell (2014). J. Power Sources 268, 315-325. 